\title{
Erratum to: Correlations between 23S rRNA genes and erythromycin resistance in Campylobacter jejuni
}

\author{
Takuya Nakajima • Akihiro Tazumi • \\ Shigeyuki Nakanishi • Jiru Xu • Lei Han • \\ Naoaki Misawa • John E. Moore • Beverley C. Millar • \\ Motoo Matsuda
}

Published online: 19 August 2012

(C) Springer-Verlag and the University of Milan 2012

\section{Erratum to: Annals of Microbiology}

\section{DOI 10.1007/s13213-011-0403-6}

The original version of this article unfortunately contained a mistake. Legend to Fig. 1 of the paper, lane 2. $81116[+(\mathrm{D})]$ should be corrected to lane 2. OH4382 (019) [+(B)].

The online version of the original article can be found at http://dx.doi.org/ 10.1007/s13213-011-0403-6.

T. Nakajima $\cdot$ A. Tazumi $\cdot$ S. Nakanishi $\cdot$ M. Matsuda $(\bowtie)$

Laboratory of Molecular Biology,

Graduate School of Environmental Health Sciences,

Azabu University,

Fuchinobe 1-17-71,

Chuo-ku, Sagamihara 252-5201, Japan

e-mail: matsuda@azabu-u.ac.jp

\section{J. Xu $\cdot$ L. Han}

Department of Immunology and Pathogenic Biology,

School of Medicine, Xi'an-Jiaotong University,

Xi'an 760001, China

\section{N. Misawa}

Department of Veterinary Public Health Laboratory,

Faculty of Agriculture, University of Miyazaki,

Miyazaki 889-2192, Japan

J. E. Moore · B. C. Millar

Department of Bacteriology,

Northern Ireland Public Health Laboratory, Belfast City Hospital,

Belfast BT9 7AD Northern Ireland, United Kingdom

\section{J. E. Moore}

School of Biomedical Sciences, University of Ulster,

Colerain BT52 1SA, Northern Ireland, United Kingdom 